\title{
Advanced bismuth-doped lead-germanate glass for broadband optical gain devices
}

\author{
M. Hughes, ${ }^{*}$ T. Suzuki, and Y. Ohishi \\ Toyota Technological Institute, 2-12, Hisakata, Tempaku, Nagoya 468-8511, Japan \\ *Corresponding author: mark@toyota-ti.ac.jp
}

Received February 28, 2008; revised June 4, 2008; accepted June 15, 2008; posted June 23, 2008 (Doc. ID 93173); published July 30, 2008

\begin{abstract}
We fabricated a series of glasses with the composition 94.7- $\chi \mathrm{GeO}_{2}-5 \mathrm{Al}_{2} \mathrm{O}_{3}-0.3 \mathrm{Bi}_{2} \mathrm{O}_{3}-\chi \mathrm{PbO}(\chi=0-24 \mathrm{~mol}$. \%). Characteristic absorption bands of bismuth centered at 500, 700, 800, and $1000 \mathrm{~nm}$ were observed. Adding $\mathrm{PbO}$ was found to decrease the strength of bismuth absorption. The addition of $3 \%-4 \% \mathrm{PbO}$ resulted in a $50 \%$ increase in lifetime, a 20 -fold increase in quantum efficiency, and a 28 -fold increase in the product of emission cross section and lifetime on the $0 \% \mathrm{PbO}$ composition. We propose that the $800 \mathrm{~nm}$ absorption band relates a different bismuth center than the other absorption bands. (C) 2008 Optical Society of America

OCIS codes: $300.2530,140.3380$.
\end{abstract}

\section{INTRODUCTION}

The invention of the erbium doped fiber amplifier (EDFA) in 1987 [1] was instrumental in allowing long distance data transmission through silica fiber and was a significant improvement on electronic repeaters that required conversion between optical and electronic signals. By a quirk of nature an emission band of erbium, which dictates the gain bandwidth of the EDFA, sits neatly in the low-loss window of silica. The technology behind silica fiber is now mature; its structure and properties are well understood, and the loss achievable in silica fiber comes close to its theoretical minimum. Until recently the presence of the hydroxyl impurity in silica introduced an overtone absorption around $1400 \mathrm{~nm}$ that effectively divided the region of lowest attenuation into two separate windows. In 1998, Lucent Technologies introduced the AllWave fiber that contains less than 1 part in $10^{9}$ hydroxyl ions. This ultradry fiber effectively gives one continuous low-loss window spanning $\sim 1200-1600 \mathrm{~nm}$. The gain bandwidth of the EDFA spans only a small fraction of this continuous low-loss window. Doping with other rare earths could allow wavelengths not covered by the EDFA to be used, but problems associated with the vibrational structure of silica prevent its use as an amplifier medium when doped with ions such as praseodymium, thulium, and dysprosium. Efficient optical amplification can be obtained from these dopants in nonoxide glass hosts; for instance, a praseodymium doped fiber amplifier with a signal gain of $40 \mathrm{~dB}$ at $1.3 \mu \mathrm{m}$ [2] and a thulium doped fiber amplifier with a maximum gain of 28 and $35 \mathrm{~dB}$ at 1.47 [3] and $1.65 \mu \mathrm{m}$ [4], respectively, have been demonstrated. However, the gain bandwidths of these devices are still relatively narrow, and they have poor compatibility with a silica based fiber. Fiber Raman amplifiers can achieve broadband amplification in silica glass; however, they require high pump powers and complex pumping schemes. One possible solution is to use a fiber amplifier doped with an ion that has a broad emission band that could replace or complement the EDFA. Transition metals are well known for their broad absorption and emission bands, for example, vanadium doped gallium-lanthanumsulphide (V:GLS) glass displays emission centered at $\sim 1500 \mathrm{~nm}$ with a full width at half-maximum (FWHM) of $\sim 500 \mathrm{~nm}$ [5]. However, similar to other transition metal doped glasses, V:GLS has a relatively low quantum efficiency $(\mathrm{QE})$ and a lifetime of $4 \%$ and $30 \mu \mathrm{s}$, respectively; this indicates that it may have a high laser threshold.

Recently, Fujimoto and Nakatsuka [6,7] discovered a new broadband infrared emission from bismuth-doped silica glass and demonstrated $1300 \mathrm{~nm}$ optimal amplification with $800 \mathrm{~nm}$ excitation. Later, bismuth-doped glasses started to attract much attention since Dianov et al. [8] demonstrated laser action between 1150 and $1300 \mathrm{~nm}$ in a bismuth-doped aluminosilicate fiber. Ultrabroad emission with an FWHM of $\sim 600 \mathrm{~nm}$ has also been observed in a bismuth-doped soda-lime-silicate glass [9]. This implies the exciting possibility of developing a broadband optical fiber amplifier based on bismuth-doped glass for use in fiber optic communications that could overcome the problem of limited gain bandwidth of the EDFA. The optical properties of a variety of bismuth-doped glasses including $\mathrm{GeO}_{2}-\mathrm{SrO}-\mathrm{Al}_{2} \mathrm{O}_{3}$ [10], $\mathrm{Li}_{2} \mathrm{O}-\mathrm{Al}_{2} \mathrm{O}_{3}-\mathrm{SiO}_{2} \quad$ [11], and $\mathrm{B}_{2} \mathrm{O}_{3}-\mathrm{BaO}-\mathrm{Al}_{2} \mathrm{O}_{3}$ [12] have been investigated. Of these, germanate glasses are particularly attractive because optical amplification has been demonstrated in them [13], and the change of host from silica to germanium can greatly enhance the transmittance of the glass and reduce the melting temperature [14]. It has been reported that the maximum transmission of bismuth-doped silicate glass, prepared by the conventional melt-quench technique, was $30 \%$ in a $2 \mathrm{~mm}$ thick sample; this was due to bubbles in the glass [6]. For the bismuth-doped leadgermanate glass in this paper; we found a maximum transmission of $80 \%$ in a $5 \mathrm{~mm}$ thick sample. In bismuth- 
doped crystals, assignment of the bismuth oxidation state has generally been made unambiguously. In bismuthdoped glasses near-infrared emission has often been observed; however, there is a lot of uncertainty as to the oxidation state of bismuth in glasses, and most of the oxidation state assignments were made tentatively. The near-infrared emission of bismuth-doped glasses has been attributed to $\mathrm{Bi}^{+}[12], \mathrm{Bi}^{5+}[6,15]$, and bismuth metal clusters [16].

In this paper we demonstrate an improvement to the $\mathrm{Bi}_{2} \mathrm{O}_{3}$ doped $\mathrm{GeO}_{2}-\mathrm{Al}_{2} \mathrm{O}_{3}$ (GAB) glass system, in which broadband optical amplification has already been demonstrated [13], through the addition of $\mathrm{PbO}$, which is now referred to as GAPB glass. To the best of our knowledge this paper is the first time the optical properties of bismuth-doped lead-germanate glass have been reported and the first time the $\mathrm{QE}$ as a function of glass composition for a bismuth-doped glass has been reported. We initially tried reproducing the GAB glass reported in [13]. After finding that the bismuth appeared to be inhomogeneously distributed we tried various codopants including $\mathrm{LiO}$ and $\mathrm{PbO}$ to improve this. Both of these codopants improved the homogeneity; however, $\mathrm{LiO}$ reduced the emission intensity, whereas $\mathrm{PbO}$ increased it and gave an unexpected color change. This led to the experiments reported in this paper. In this paper we measured the absorption, emission, and lifetime of 16 samples with $\mathrm{PbO}$ contents between $0 \%$ and $24 \%$ at excitation wavelengths of 514, 700, 800, and $974 \mathrm{~nm}$. For the sake of clarity and a practical number of figures we have shown different $\mathrm{PbO}$ content glasses in the various figures in order to highlight the trends we observed.

\section{EXPERIMENTAL}

\section{A. Glass Melting}

$\mathrm{GAB}$ and GAPB glasses were prepared by mixing 94.7- $\chi \mathrm{GeO}_{2}-5 \mathrm{Al}_{2} \mathrm{O}_{3}-0.3 \mathrm{Bi}_{2} \mathrm{O}_{3}-\chi \mathrm{PbO}(\chi=0-24 \mathrm{~mol}$. \% $)$ in a dry-nitrogen-purged glove box. The glasses were then melted in an electrical furnace, with an $\mathrm{N}_{2}$ atmosphere, in alumina crucibles. Subsequently the glass melts were quenched by pouring them onto stainless steel plates preheated to $450^{\circ} \mathrm{C}$. Each glass was then annealed at $600^{\circ} \mathrm{C}$ for $3 \mathrm{~h}$. Finally the glasses were cut to a size of around $20 \mathrm{~mm} \times 20 \mathrm{~mm} \times 2.5 \mathrm{~mm}$ and then well polished with progressively finer wet polishing paper. The melting temperature for the $0 \% \mathrm{PbO}(\mathrm{GAB})$ glass was $1540^{\circ} \mathrm{C}$. The melting temperature for the $24 \% \mathrm{PbO}$ glass was $1200^{\circ} \mathrm{C}$, rising to $1370^{\circ} \mathrm{C}$ for the $2 \% \mathrm{PbO}$ glass. However, differential thermal analysis (DTA) of the glasses indicated that the melting temperature for all the $\mathrm{PbO}$ containing glasses was around $1170^{\circ} \mathrm{C}$. The increase in melting temperature with a decreasing $\mathrm{PbO}$ content was necessary to facilitate pouring of the glass, since the viscosity of the glass increased significantly with a decreasing $\mathrm{PbO}$ content. Glasses with $0 \% \mathrm{PbO}$ were dark brown in appearance; with $\mathrm{PbO}$ concentrations up to $3 \%$, the glasses were an opaque dark pink. Glasses with a $4 \%-12 \% \mathrm{PbO}$ content were a translucent pale pink, which became progressively paler with an increasing $\mathrm{PbO}$ content. Above $12 \%$ the $\mathrm{PbO}$ content of all the glasses appeared colorless. We chose a fixed composition of $5 \% \mathrm{Al}_{2} \mathrm{O}_{3}$ in this paper be- cause this has been shown to maximize the emission lifetime and intensity in GAB glass [17].

\section{B. Spectroscopic Measurements}

Absorption spectra were taken on a PerkinElmer Lambda 900 spectrophotometer over a range of $175-3300 \mathrm{~nm}$ with a resolution of $\pm 0.1 \mathrm{~nm}$. Various laser sources were used to obtain photoluminescence (PL) spectra: a $974 \mathrm{~nm}$ Furakawa laser diode, a Coherent 890 Ti:sapphire laser tuned to 700 or $800 \mathrm{~nm}$, and a Spectra-Physics argon ion laser tuned to $514 \mathrm{~nm}$. The $974 \mathrm{~nm}$ laser source was electronically modulated, giving a $1 / e$ fall time of $\sim 250 \mathrm{~ns}$, whereas the 514, 700, and $800 \mathrm{~nm}$ laser sources were focused with a microscope objective and modulated with a mechanical chopper at the focus waist, which gave a 1/e fall time of $\sim 50 \mu \mathrm{s}$. PL spectra were obtained by dispersing the fluorescence generated by laser sources in a Jasco CT-25C monochromator that used a 600 lines/mm grating blazed at $1000 \mathrm{~nm}$; the slit width was $\sim 1 \mathrm{~mm}$ that corresponded to a resolution of $\sim 10 \mathrm{~nm}$. The $974 \mathrm{~nm}$ excitation was blocked with a $980 \mathrm{~nm}$ notch filter, and the 514, 700, and $800 \mathrm{~nm}$ excitation was blocked with an $850 \mathrm{~nm}$ long pass filter. Detection was realized with a Hamamatsu H9170 NIR photomultiplier tube (PMT), with a fall time of $1.7 \mathrm{~ns}$, coupled with standard phase sensitive detection. All spectral measurements were corrected for the wavelength dependent response of the measurement system by calculating a correction spectra $[C(\lambda)]$ with $C(\lambda)$ $=I_{\text {cal }}(\lambda) / I_{\text {meas }}(\lambda)$, where $I_{\text {meas }}(\lambda)$ is the luminescence spectrum of an Ushio calibrated white light source measured by the detection system, and $I_{\text {cal }}(\lambda)$ is the luminescence spectrum of the calibrated white light source supplied by the manufacturer. Transient fluorescence measurements were made with the same system used for spectral measurements, except the transient signal was captured with a Yokogawa DL1620 $200 \mathrm{MHz}$ oscilloscope and averaged $\sim 10,000$ times.

$\mathrm{QE}$ measurements were taken with the same system used for spectral measurements, except the samples with dimensions of $\sim 3 \mathrm{~mm} \times 3 \mathrm{~mm} \times 1 \mathrm{~mm}$ were placed in a Labsphere 4P-GPS-040-SF integrating sphere with a diameter of $\sim 10 \mathrm{~cm}$, and the signal was detected with a Hamamatsu G5852-11 InGaAs detector. The samples were mounted behind a baffle such that there was no direct line-of-sight between the sample and the exit port and angled such that reflected excitation light was directed away from the entrance port. A "photons out/ photons in" method similar to that described in $[18,19]$ for calculating the $\mathrm{QE}$ was used. The number of photons absorbed was taken to be proportional to the difference between the area under the laser line spectra with the sample present $\left[I_{\text {sample }}(\lambda)\right]$ and without the sample present $\left[I_{\text {sphere }}(\lambda)\right]$. The number of photons emitted was taken to be proportional to the area under the emission spectra $\left[I_{\mathrm{PL}}(\lambda)\right]$. The spectra were corrected with a correction spectra $[C(\lambda)]$. A correction for photon energy was also made since a higher photon flux is required at longer wavelengths to produce the same irradiance per unit area as at shorter wavelengths by multiplying by the wavelength. Hence the QE ( $\eta_{\mathrm{QE}}$ ) was calculated with 


$$
\eta_{\mathrm{QE}}=\frac{\int \lambda I_{\mathrm{PL}}(\lambda) C(\lambda) \mathrm{d} \lambda}{\int \lambda I_{\text {sphere }}(\lambda) C(\lambda) \mathrm{d} \lambda-\int \lambda I_{\text {sample }}(\lambda) C(\lambda) \mathrm{d} \lambda} .
$$

There was found to be a lot of variability in the QE measurements of the weakly absorbing samples; this was caused by difficulty in measuring the amount of excitation laser light that was absorbed. To overcome this, laser line spectra were taken up to ten times for each QE measurement and 10-15 QE measurements were made for each sample, totaling 1500 spectra for the QE measurements in this paper. Differential scanning callorimetry (DSC) measurements were made with a Rigaku Thermoplus DSC 8270. Refractive index measurements were made with a Metricon 2010 prism coupler.

\section{RESULTS AND DISCUSSION}

\section{A. Absorption Measurements}

Figure 1 shows the absorption spectra of some GAPB glasses with various $\mathrm{PbO}$ concentrations. Four main absorption bands centered around 500, 700, 800, and $1000 \mathrm{~nm}$ are identified, which is similar to the characteristic bismuth absorption observed in other glasses $[10,11,20]$. It can be seen that as the $\mathrm{PbO}$ content increases the absorption bands attributed to bismuth tend to decrease in strength. This might occur because the addition of $\mathrm{PbO}$ may permit the bismuth dopant to be incorporated as a structural component of the glass, rather than an optically active ion, since many authors have proposed a structural similarity between lead-rich and bismuth-rich glasses [21]. It is also noted that the transparency of the glass increases with an increasing $\mathrm{PbO}$ content.

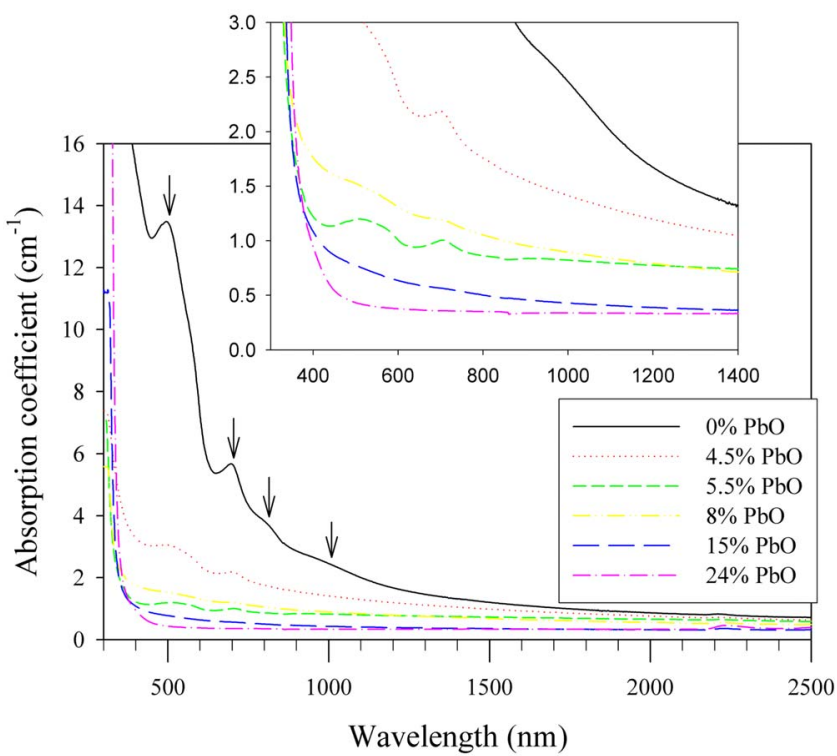

Fig. 1. (Color online) Absorption spectra of GAPB glasses with various $\mathrm{PbO}$ concentrations. The identified bismuth absorption bands are indicated with arrows. Inset shows a close-up of the weakly absorbing samples.

\section{B. Emission Spectra Measurements}

Figure 2(a) shows the PL spectra of some GAPB glasses with various $\mathrm{PbO}$ concentrations taken using a $974 \mathrm{~nm}$ laser excitation source. One main emission band can be observed centered at $\sim 1100 \mathrm{~nm}$; this emission band is observed in all the glasses except the $24 \% \mathrm{PbO}$ glass. A weaker emission band that peaks between 1330 and $1475 \mathrm{~nm}$ and varies in relative intensity with the $\mathrm{PbO}$ content of the glass is also observed. A $1330 \mathrm{~nm}$ emission band is apparent in the $0 \% \mathrm{PbO}$ content glass, which then fades in glasses with a $2 \%-10 \% \mathrm{PbO}$ content. As the $\mathrm{PbO}$ content is increased past $10 \%$ (not shown for clarity) an emission band peaking at $1475 \mathrm{~nm}$ is observed; the intensity of this band steadily increases with the $\mathrm{PbO}$ content. In Fig. 2(b) the emission spectrum of the $0 \% \mathrm{PbO}$ content glass has been deconvoluted with two Gaussians. The fit of the two Gaussians, which are centered at 1090 and $1330 \mathrm{~nm}$, is very consistent with the observed spectrum. Emission peaks at 1100 and $1350 \mathrm{~nm}$ have also been observed in bismuth-doped $\mathrm{Li}_{2} \mathrm{O}-\mathrm{Al}_{2} \mathrm{O}_{3}-\mathrm{SiO}_{2}$ glass under $900 \mathrm{~nm}$ excitation [11]; however, the $1350 \mathrm{~nm}$ band was almost as intense as the $1100 \mathrm{~nm}$ band. The deconvolution of the emission spectrum of the $22 \% \mathrm{PbO}$ glass (not shown) revealed two Gaussians centered at 1110 and $1475 \mathrm{~nm}$; however, it is unclear if this $1475 \mathrm{~nm}$ emission band is a re-emergence of the $1330 \mathrm{~nm}$ emission band observed in the $0 \% \mathrm{PbO}$ content glass that has been redshifted or a separate emission band related to a different phenomenon. Increasing the $\mathrm{PbO}$ content from $22 \%$ to $24 \%$ causes the emission spectra to undergo a dramatic

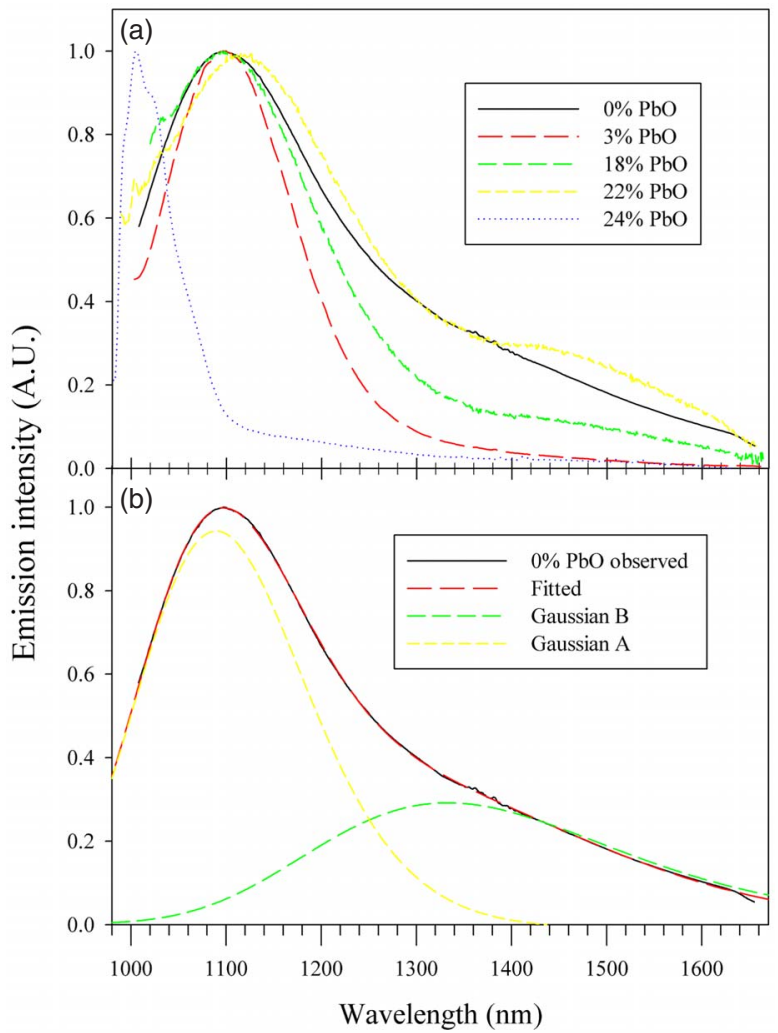

Fig. 2. (Color online) (a) PL spectra, excited at $974 \mathrm{~nm}$, of GAPB glasses with various $\mathrm{PbO}$ concentrations. (b) Deconvolution of the emission spectrum of the glass with a $0 \% \mathrm{PbO}$ content with two Gaussians. 


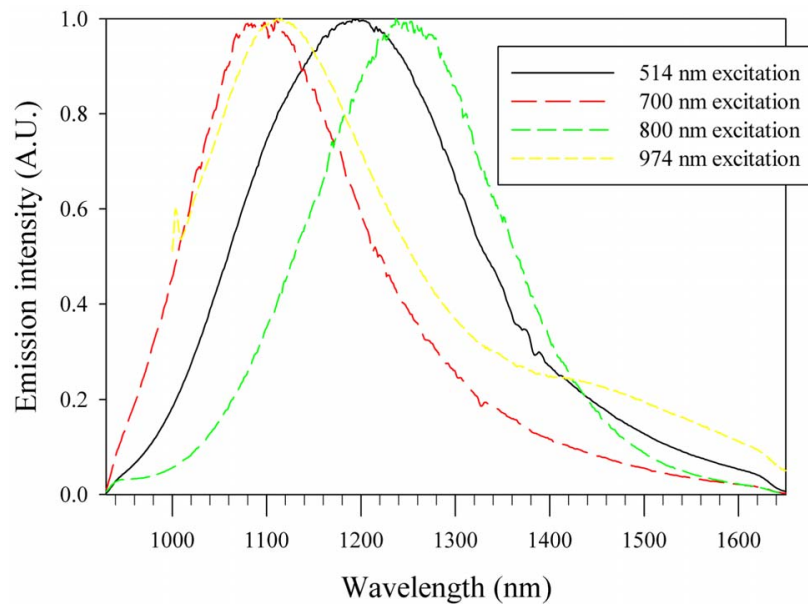

Fig. 3. (Color online) PL spectra, excited at 514, 700, 800, and $974 \mathrm{~nm}$, of GAPB glasses with a $20 \% \mathrm{PbO}$ content.

change. The peak shifts from 1100 to $1000 \mathrm{~nm}$ and the width decrease sharply. It is noteworthy that this dramatic change in emission occurs at $24 \% \mathrm{PbO}$, where the $\mathrm{GeO}_{2}-\mathrm{PbO}$ ratio is 2.95 since a $\mathrm{GeO}_{2}-\mathrm{PbO}$ ratio of near 3 has been identified as an optimum ratio for stable glass formation by analysis of the phase diagram of the $\mathrm{GeO}_{2}-\mathrm{PbO}$ binary system [22]. We therefore tentatively suggest that a phase change is responsible for the change in emission spectrum.

Figure 3 shows the bismuth emission spectra from a $20 \% \mathrm{PbO}$ sample, excited at wavelengths of $514,700,800$, and $974 \mathrm{~nm}$, which roughly equates to exciting into each of the four absorption bands identified in Fig. 1. It appears that $700 \mathrm{~nm}$ excitation activates the same characteristic $1100 \mathrm{~nm}$ emission band as $974 \mathrm{~nm}$ excitation, but the $1475 \mathrm{~nm}$ emission band is less apparent. The emission spectra from $700 \mathrm{~nm}$ excitation for $\mathrm{PbO}$ concentrations of $0 \%$ to $24 \%$ (not shown) were roughly similar to the spectrum in Fig. 3. Excitation at $800 \mathrm{~nm}$ appears to activate a single $1250 \mathrm{~nm}$ emission band; this is similar to the emission observed from $75 \mathrm{~B}_{2} \mathrm{O}_{3}-20 \mathrm{BaO}-5 \mathrm{Al}_{2} \mathrm{O}_{3}-2 \mathrm{Bi}_{2} \mathrm{O}_{3}$ glass under $808 \mathrm{~nm}$ excitation [12]. Under $514 \mathrm{~nm}$ excitation a $1200 \mathrm{~nm}$ emission band is observed. In the emission spec-

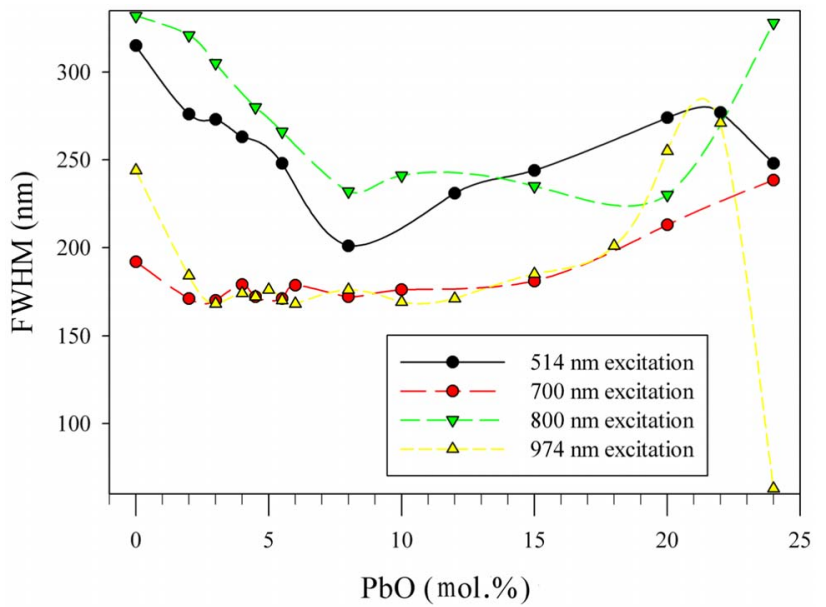

Fig. 4. (Color online) Emission FWHM as a function of the $\mathrm{PbO}$ content for various excitation wavelengths. Curves are a guide for the eye. tra from $514 \mathrm{~nm}$ excitation for $\mathrm{PbO}$ concentrations of $2 \%$ $10 \%$ (not shown) a single $1100 \mathrm{~nm}$ emission band was observed, which was broadly similar to the emission spectra for 700 and $974 \mathrm{~nm}$ excitation shown in Fig. 3.

Figure 4 shows how the width of emission varies as a function of the $\mathrm{PbO}$ content for the different pump wavelengths. Excitation at 974 and $700 \mathrm{~nm}$ gives similar dependencies on the $\mathrm{PbO}$ content as do 800 and $514 \mathrm{~nm}$ excitation. For $974 \mathrm{~nm}$ excitation the addition of $\mathrm{PbO}$ initially reduces the emission width from GAB glass, where it remains constant until $\sim 12 \% \mathrm{PbO}$, after which it steadily increases to reach a maximum at $\sim 22 \% \mathrm{PbO}$.

\section{Emission Lifetime Measurements}

Figure 5 shows the emission decay profiles of GAPB glasses with $3 \%$ and $22 \% \mathrm{PbO}$ contents. The fluorescence decay profiles were found to be nonexponential but could be accurately described using the stretched exponential function

$$
I(t)=y_{0}+I_{0} \exp \left(-\left(\frac{t}{\tau_{0}}\right)^{\beta}\right),
$$

where $I_{0}$ is the initial fluorescence intensity, $y_{0}$ is the offset, $\tau_{0}$ is the characteristic fluorescence lifetime, and $\beta$ is the stretch factor. The closer $\beta$ is to zero the more the function deviates from a single exponential. The stretched exponential function has been shown to describe many relaxation processes in amorphous and crystalline materials, such as nuclear relaxation [23], magnetic susceptibility relaxation [23], fluorescence decay [5,24-28], and photoinduced dichroism [29]. Though stretched exponential behavior has been observed in many relaxation processes, particularly in disordered materials such as glasses, there has been considerable debate as to the physical interpretation of the characteristic lifetime $\tau_{0}$ and stretch factor $\beta$. Stretched exponential relaxation is commonly interpreted as a sum of pure exponential decays with a probability distribution $P$ of $\tau$ lifetime values for a given value of $\beta$ [30]. Recently, the probability distribution $P\left(\tau_{0} / \tau\right)$ of the stretched exponential function for different $\beta$ values have been calculated [30-32]. Analysis of these distributions leads to the following physical inter-

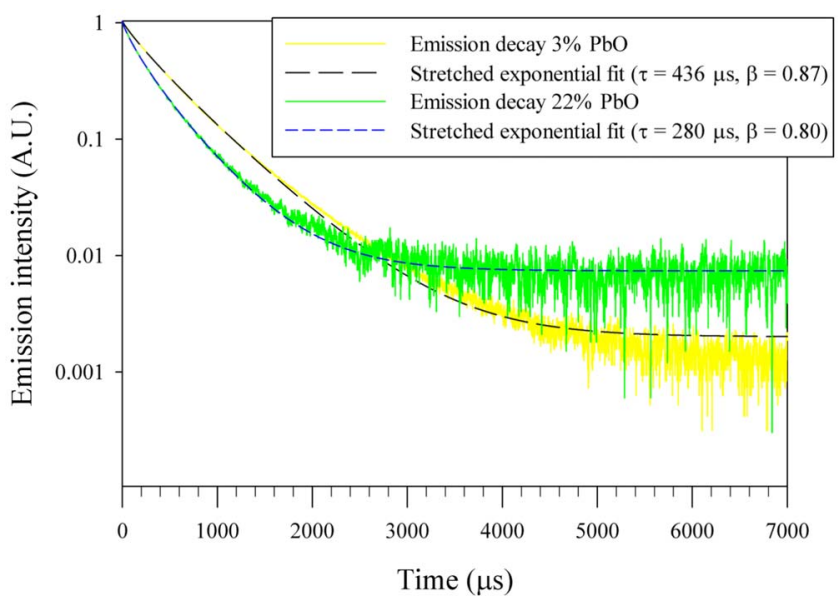

Fig. 5. (Color online) Emission decay profiles of GAPB glasses with $\mathrm{PbO}$ contents of $3 \%$ and $22 \%$. 


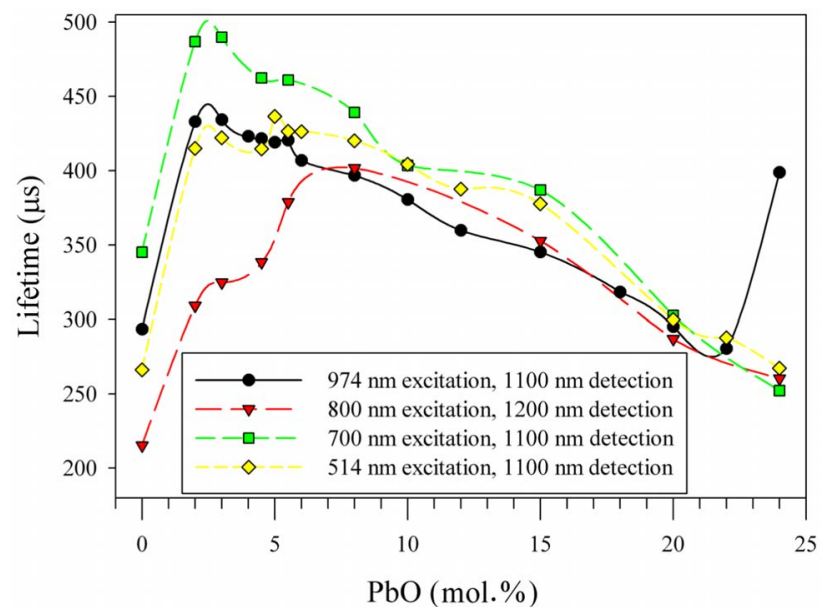

Fig. 6. (Color online) Emission lifetime, detected at the emission peak, as a function of the $\mathrm{PbO}$ content for excitation wavelengths of 514, 700, 800, and $974 \mathrm{~nm}$. Curves are a guide for the eye.

pretations: that $\tau_{0}$ is that $\tau$, which is equally likely to be less than $\tau_{0}$ as it is to be greater, and that $\beta$ is a measure of the intrinsic long lifetime cutoff of $P\left(\tau_{0} / \tau, \beta\right)$ [30].

Figure 6 shows the emission lifetime measured at approximately the peak of the emission. For $974 \mathrm{~nm}$ excitation there is an initial $50 \%$ increase in lifetime with the addition of $\mathrm{PbO}$ that then steadily decreases to approximately the $0 \% \mathrm{PbO}$ value at $22 \% \mathrm{PbO}$, before increasing again at $24 \% \mathrm{PbO}$. There is a very similar trend for $700 \mathrm{~nm}$ excitation, with the exception of $24 \% \mathrm{PbO}$, which has already been identified as a special case. The trend for $514 \mathrm{~nm}$ excitation is similar to the trend for 700 and $974 \mathrm{~nm}$ excitation but with longer lifetimes. However, the trend for $800 \mathrm{~nm}$ excitation is different from other excitation wavelengths with the maximum lifetime occurring at $\sim 10 \% \mathrm{PbO}$.

Figure 7 shows the detection wavelength-dependent lifetime of the $5 \% \mathrm{PbO}$ content glass at the four different excitation wavelengths. The trends for 514, 700, and $974 \mathrm{~nm}$ excitation follow a broadly similar pattern with the maximum lifetime occurring at slightly longer wave-

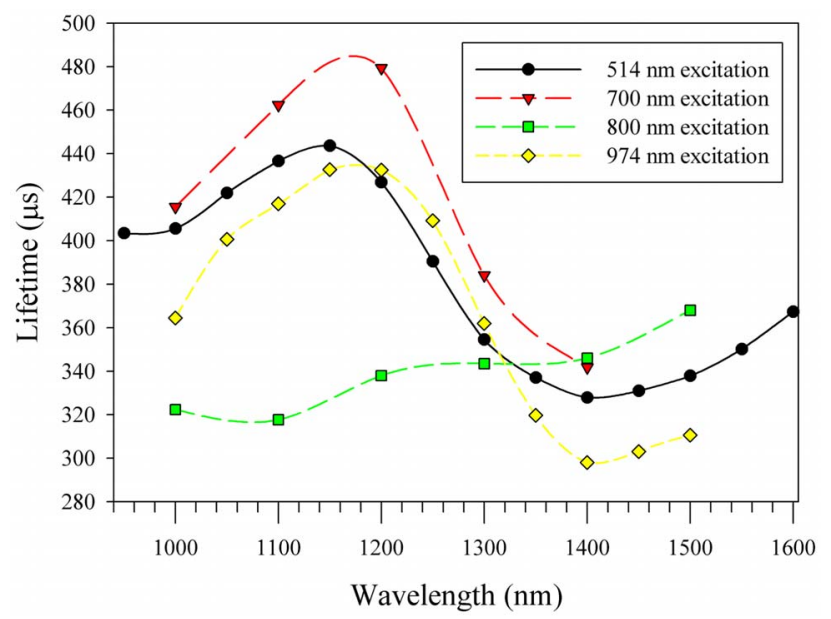

Fig. 7. (Color online) Lifetime spectra of $5 \% \mathrm{PbO}$ GAPB glass for excitation wavelengths of $514,700,800$, and $974 \mathrm{~nm}$. Curves are a guide for the eye. lengths than the maximum emission intensity; the lifetime then reaches a minimum at around $1400 \mathrm{~nm}$ and then increases at longer wavelengths. For $800 \mathrm{~nm}$ excitation the general trend is for a steadily increasing lifetime with an increasing detection wavelength, with a small increase close to the emission peak at $1250 \mathrm{~nm}$.

\section{Quantum Efficiency Measurements}

Figure 8 shows the QE of GAPB glasses, excited at $974 \mathrm{~nm}$, as a function of the $\mathrm{PbO}$ content of the glass. The error bars show one standard deviation from the mean. We chose to use $974 \mathrm{~nm}$ excitation for the QE measurements because broadband optical amplification has been demonstrated in GAB glass using $974 \mathrm{~nm}$ excitation [13]. Figure 8 also shows the product of the peak emission cross section and the emission lifetime $\left(\sigma_{\mathrm{em}} \tau\right)$, which is an important parameter for a gain medium since it is inversely proportional to the laser threshold [33]. The peak emission cross section $\left(\sigma_{\mathrm{em}}\right)$ was estimated from the Füchtbauer-Landenburg equation by assuming a Gaussian-shaped emission band [34] and is given by

$$
\sigma_{\mathrm{em}}=\sqrt{\frac{\ln 2}{\pi}} \frac{\lambda_{0}^{2}}{4 \pi n^{2} \tau_{\mathrm{rad}} \Delta v},
$$

where $\lambda_{0}$ is the peak emission wavelength, $\Delta v$ is the FWHM of the emission in units of energy, $n$ is the refractive index, $c$ is the speed of light, and $\tau_{\text {rad }}$ is the radiative lifetime calculated from the measured lifetime $(\tau)$ by $\tau_{\text {rad }}$ $=\tau / \mathrm{QE}$. Figure 8 shows that the QE has a similar dependence on the $\mathrm{PbO}$ content as the lifetime. This indicates that the radiative rate remains constant, and the nonradiative rate increases as the $\mathrm{PbO}$ content is increased; this could be caused by an increase in maximum phonon energy as the $\mathrm{PbO}$ content is increased. An increase in maximum phonon energy would increase the probability of nonradiative decay by decreasing the number of phonons required for a multiphonon emission process. The $\mathrm{QE}$ has a peak of $\sim 60 \%$ at $\sim 4 \% \mathrm{PbO}$; this represents a 20-fold increase in $\mathrm{QE}$ on GAB glass. These $\mathrm{QE}$ measurements compare to $11 \%$ for bismuth doped $\mathrm{Li}_{2} \mathrm{O}-\mathrm{Al}_{2} \mathrm{O}_{3}-\mathrm{SiO}_{2}$ glass when excited at $974 \mathrm{~nm}$ [35]. Considering how the emission spectra changes as a function of the $\mathrm{PbO}$ content, it appears that when the long wave-

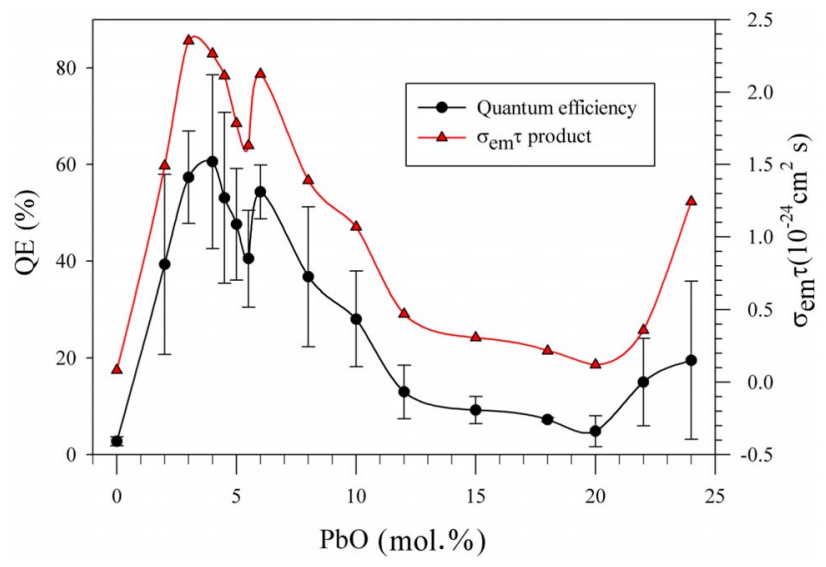

Fig. 8. (Color online) $\mathrm{QE}$ and $\sigma_{\mathrm{em}} \tau$ as a function of the $\mathrm{PbO}$ content. Curves are a guide for the eye. 
length component of the emission is present, as in $0 \%$ and $10 \%-22 \% \mathrm{PbO}$, the $\mathrm{QE}$ is reduced. Comparing Figs. 4, 6, and 8 indicates that an increase in lifetime and QE occurs with a narrowing emission width. The $\sigma_{\mathrm{em}} \tau$ product has a peak of $\sim 2.4 \times 10^{-24} \mathrm{~cm}^{2} \mathrm{~s}$ at $\sim 3 \% \mathrm{PbO}$; this represents a 28 -fold increase on GAB glass. However, glass at this composition has low transparency and is difficult to prepare; further development of the glass fabrication process could overcome this, but as a compromise $89 \mathrm{GeO}_{2}-6 \mathrm{PbO}-5 \mathrm{Al}_{2} \mathrm{O}_{3}-0.3 \mathrm{Bi}_{2} \mathrm{O}_{3}$ glass is suggested for further development as a gain medium. The peak $\sigma_{\mathrm{em}} \tau$ of $\sim 2.4 \times 10^{-24} \mathrm{~cm}^{2} \mathrm{~s}$ declared in this paper is slightly lower than the $\sigma_{\mathrm{em}} \tau$ for bismuth emission reported by other authors: $5.1 \times 10^{-24} \mathrm{~cm}^{2} \mathrm{~s}$ for bismuth-doped $\mathrm{Na}_{2} \mathrm{O}-\mathrm{CaO}-\mathrm{MgO}-\mathrm{Al}_{2} \mathrm{O}_{3}-\mathrm{SiO}_{2}$ glass [9], $6.1 \times 10^{-24} \mathrm{~cm}^{2} \mathrm{~s}$ for bismuth-doped $\mathrm{Li}_{2}-\mathrm{Al}_{2} \mathrm{O}_{3}-\mathrm{SiO}_{2}$ glass [11], 4.2 $\times 10^{-24} \mathrm{~cm}^{2} \mathrm{~s}$ for bismuth-doped $\mathrm{GeO}_{2}-\mathrm{Al}_{2} \mathrm{O}_{3}$ glass [17], and $6.1 \times 10^{-24} \mathrm{~cm}^{2} \mathrm{~s}$ for bismuth-doped $\mathrm{GeO}_{2}-\mathrm{Al}_{2} \mathrm{O}_{3}-\mathrm{Na}_{2} \mathrm{O}$ glass [15]. The $\sigma_{\text {em }} \tau$ reported by these authors was calculated using a similar method to this paper; however, the measured lifetime rather that the radiative lifetime was used. These reports may therefore be an overestimate if the QE is less than $100 \%$.

Since optical gain of $3.65 \mathrm{~dB}$ at $1270 \mathrm{~nm}$ under $974 \mathrm{~nm}$ excitation has been demonstrated in GAB glass [13], the 27 -fold increase in $\sigma_{\mathrm{em}} \tau$ obtained with the addition of $3 \%$ $\mathrm{PbO}$ to GAB glass is highly significant because it implies that a much larger optical gain could be demonstrated in the glass; this will be the subject of further work after additional enhancement of the glass composition and fabrication process.

\section{MODEL OF EMISSION}

The following differences have been observed between the emission properties of the $800 \mathrm{~nm}$ absorption band to the 500,700 , and $1000 \mathrm{~nm}$ absorption bands.

- Emission peaking at $1250 \mathrm{~nm}$ rather than $1100 \mathrm{~nm}$.

- Different dependence of emission FWHM as a function of the $\mathrm{PbO}$ content.

- Different trend in emission lifetime as a function of the $\mathrm{PbO}$ content.

- Different dependence of lifetime as a function of the emission wavelenth.

The different emission wavelength and the different lifetime dependence of the emission wavelength (Fig. 7) indicate that the $1250 \mathrm{~nm}$ emission band observed under $800 \mathrm{~nm}$ excitation is a different emission band to the $1330 \mathrm{~nm}$ emission band observed under $974 \mathrm{~nm}$ excitation [Fig. 2(b)]. The fact that the $1250 \mathrm{~nm}$ emission band, observed under $800 \mathrm{~nm}$ excitation, is present in all $\mathrm{PbO}$ content glasses, whereas the $1330 \mathrm{~nm}$ emission band observed under $974 \mathrm{~nm}$ excitation is observed only in the $0 \%$ $\mathrm{PbO}$ glass, also backs up this hypothesis. We therefore propose that the 500,700, and $1000 \mathrm{~nm}$ absorption bands are associated with the same bismuth emission center (emission center $A$ ) and the $800 \mathrm{~nm}$ absorption band is associated with a different emission center (emission center $B)$. However, because there are some similarities between the 500 and $800 \mathrm{~nm}$ absorption bands such as the longer emission wavelength at certain $\mathrm{PbO}$ concentrations under
$514 \mathrm{~nm}$ excitation, and in the emission FWHM as a function of the $\mathrm{PbO}$ content, we propose that emission center $B$ may also accommodate a $500 \mathrm{~nm}$ absorption band.

\section{CONCLUSIONS}

The characteristic absorption bands of bismuth, centered at $500,700,800$, and $1000 \mathrm{~nm}$, were observed in bismuthdoped GAB and GAPB glass. The addition of $\mathrm{PbO}$ to GAB glass was found to decrease the strength of the absorption bands attributed to bismuth; this indicates that $\mathrm{PbO}$ helps bismuth to be incorporated into the glass in an optically inactive form. Four emission bands at 1005, 1100, 1330, and 1475 were observed with $974 \mathrm{~nm}$ excitation in GAPB glasses with a $\mathrm{PbO}$ content of $0 \%-24 \%$. Excitation into the 500, 700, and $1000 \mathrm{~nm}$ absorption bands yielded broadly similar emission spectra and lifetime properties as a function of the $\mathrm{PbO}$ content of the glass; it is therefore suggested that these absorption bands belong to the same bismuth emission center. Because some fundamental differences were observed in the emission spectra and lifetime properties as a function of $\mathrm{PbO}$ when exciting into the $800 \mathrm{~nm}$ absorption band, it is suggested that this absorption band belongs to a separate bismuth emission center. We made a detailed measurement of the $\mathrm{QE}$ of GAPB glass as a function of the $\mathrm{PbO}$ content; to the best of our knowledge this is the first compositional dependent $\mathrm{QE}$ measurement for a bismuth-doped glass. The addition of the appropriate proportion of $\mathrm{PbO}$ to GAB glass resulted in a $50 \%$ increase in lifetime, a 20 -fold increase in $\mathrm{QE}$, and a 28-fold increase in $\sigma_{\mathrm{em}} \tau$.

\section{REFERENCES}

1. R. J. Mears, L. Reekie, I. M. Jauncey, and D. N. Payne, "Low-noise erbium-doped fiber amplifier operating at $1.54 \mu \mathrm{m}$," Electron. Lett. 23, 1026-1028 (1987).

2. M. Yamada, M. Shimizu, T. Kanamori, Y. Ohishi, Y. Terunuma, K. Oikawa, H. Yoshinaga, K. Kikushima, Y. Miyamoto, and S. Sudo, "Low-noise and high-power Pr3+-doped fluoride fiber amplifier," IEEE Photonics Technol. Lett. 7, 869-871 (1995).

3. T. Komukai, T. Yamamoto, T. Sugawa, and Y. Miyajima, "Upconversion pumped thulium-doped fluoride fiber amplifier and laser operating at $1.47 \mu \mathrm{m}$," IEEE J. Quantum Electron. 31, 1880-1889 (1995).

4. T. Sakamoto, M. Shimizu, M. Yamada, T. Kanamori, Y. Ohishi, Y. Terunuma, and S. Sudo, "35-dB gain Tm-doped ZBLYAN fiber amplifier operating at $1.65 \mu \mathrm{m}$," IEEE Photonics Technol. Lett. 8, 349-351 (1996).

5. M. Hughes, H. Rutt, D. Hewak, and R. Curry, "Spectroscopy of vanadium (III) doped gallium lanthanum sulphide glass," Appl. Phys. Lett. 90, 031108 (2007).

6. Y. Fujimoto and M. Nakatsuka, "Infrared luminescence from bismuth-doped silica glass," Jpn. J. Appl. Phys., Part 2 40, L279-L281 (2001).

7. Y. Fujimoto and M. Nakatsuka, "Optical amplification in bismuth-doped silica glass," Appl. Phys. Lett. 82, 3325-3326 (2003).

8. E. M. Dianov, V. V. Dvoyrin, V. M. Mashinsky, A. A. Umnikov, M. V. Yashkov, and A. N. Gur'yanov, "CW bismuth fibre laser," Quantum Electron. 35, 1083-1084 (2005).

9. Y. Arai, T. Suzuki, Y. Ohishi, S. Morimoto, and S. Khonthon, "Ultrabroadband near-infrared emission from a colorless bismuth-doped glass," Appl. Phys. Lett. 90, 261110 (2007).

10. J. Ren, J. Qiu, B. Wu, and D. Chen, "Ultrabroad infrared 
luminescence from Bi-doped alkaline earth metal germanate glasses," J. Mater. Res. 22, 1574-1577 (2007).

11. T. Suzuki and Y. Ohishi, "Ultrabroadband near-infrared emission from Bi-doped $\mathrm{Li}_{2} \mathrm{O}-\mathrm{Al}_{2} \mathrm{O}_{3}-\mathrm{SiO}_{2}$ glass," Appl. Phys. Lett. 88, 191912 (2006).

12. X.-G. Meng, J.-R. Qiu, M.-Y. Peng, D.-.P Chen, Q.-Z. Zhao, X.-W. Jiang, and C.-S. Zhu, "Infrared broadband emission of bismuth-doped barium-aluminum-borate glasses," Opt. Express 13, 1635-1642 (2005).

13. S. Zhou, H. Dong, H. Zeng, G. Feng, H. Yang, B. Zhu, and J. Qiu, "Broadband optical amplification in Bi-doped germanium silicate glass," Appl. Phys. Lett. 91, 061919 (2007).

14. M. Peng, J. Qiu, D. Chen, X. Meng, I. Yang, X. Jiang, and C. Zhu, "Bismuth and aluminium codoped germanium oxide glasses for super-broadband optical amplification," Opt. Lett. 29, 1998-2000 (2004).

15. X. Wang and H. Xia, "Infrared superbroadband emission of Bi ion doped germanium-aluminum-sodium glass," Opt. Commun. 268, 75-78 (2006).

16. M. Peng, J. Qiu, D. Chen, X. Meng, and C. Zhu, "Superbroadband $1310 \mathrm{~nm}$ emission from bismuth and tantalum codoped germanium oxide glasses," Opt. Lett. 30, 2433-2435 (2005).

17. M. Peng, C. Wang, D. Chen, J. Qiu, X. Jiang, and C. Zhu, "Investigations on bismuth and aluminum co-doped germanium oxide glasses for ultra-broadband optical amplification," J. Non-Cryst. Solids 351, 2388-2393 (2005).

18. C. E. Finlayson, A. Amezcua, P. J. Sazio, P. S. Walker, M. C. Grossel, R. J. Curry, D. C. Smith, and J. J. Baumberg, "Infrared emitting PbSe nanocrystals for telecommunications window applications," J. Mod. Opt. 52, 955-964 (2005).

19. N. C. Greenham, "Measurement of absolute photoluminescence quantum efficiencies in conjugated polymers," Chem. Phys. Lett. 241, 89-96 (1995).

20. M. Peng, C. Wang, D. Chen, J. Qiu, X. Jiang, and C. Zhu, "Investigations on bismuth and aluminum co-doped germanium oxide glasses for ultra-broadband optical amplification," J. Non-Cryst. Solids 351, 2388-2393 (2005).

21. V. N. Sigaev, I. Gregora, P. Pernice, B. Champagnon, E. N. Smelyanskaya, A. Aronne, and P. D. Sarkisov, "Structure of lead germanate glasses by Raman spectroscopy,” J. NonCryst. Solids 279, 136-144 (2001)

22. J. Wang, J. R. Lincoln, W. S. Brocklesby, R. S. Deol, C. J. Mackechnie, A. Pearson, A. C. Tropper, D. C. Hanna, and D. N. Payne, "Fabrication and optical properties of leadgermanate glasses and a new class of optical fibers doped with $\mathrm{Tm}^{3+}$," J. Appl. Phys. 73, 8066-8075 (1993).
23. J. C. Phillips, "Stretched exponential relaxation in molecular and electronic glasses," Rep. Prog. Phys. 59, 1133-1207 (1996).

24. K. C. B. Lee, J. Siegel, S. E. D. Webb, S. Leveque-Fort, M. J. Cole, R. Jones, K. Dowling, M. J. Lever, and P. M. W. French, "Application of the stretched exponential function to fluorescence lifetime imaging," Biophys. J. 81, 1265-1274 (2001).

25. R. A. L. Vallée, M. Cotlet, J. Hofkens, F. C. D. Schryver, and K. Mullen, "Spatially heterogeneous dynamics in polymer glasses at room temperature probed by single molecule lifetime fluctuations," Macromolecules $\mathbf{3 6}$, 7752-7758 (2003).

26. G. Mauckner, K. T. T. Baier, T. Walter, and F. L. Sauer, "Temperature dependent lifetime distribution of the photoluminescence S-band in porous silicon,” J. Appl. Phys. 75, 4167-4170 (1993).

27. R. Chen, "Apparent stretched-exponential luminescence decay in crystalline solids," J. Lumin. 102-103, 510-518 (2003).

28. J. Wlodarczyk and B. Kierdaszuk, "Interpretation of fluorescence decays using a power-like model," Biophys. J. 85, 589-598 (2003).

29. A. B. Seddon, D. Furniss, M. S. Iovu, S. D. Shutov, N. N. Syrbu, A. M. Andriesh, P. Hertogen, and G. J Adriaenssens, "Optical absorption and visible luminescence in Ga-La-S-O glass doped with Pr3+ ions," J. Optoelectron. Adv. Mater. 5, 1107-1113 (2003).

30. D. C. Johnston, "Stretched exponential relaxation arising from a continuous sum of exponential decays," Phys. Rev. B 74, 184430 (2006).

31. P. Hetman, B. Szabat, K. Weron, and D. Wodzinski, "On the Rajagopal relaxation-time distribution and its relationship to the Kohlrausch-Williams-Watts relaxation function," J. Non-Cryst. Solids 330, 66-74 (2003).

32. I. Svare, S. W. Martin, and F. Borsa, "Stretched exponentials with T-dependent exponents from fixed distributions of energy barriers for relaxation times in fast-ion conductors," Phys. Rev. B 61, 228-233 (2000).

33. S. Kuck, K. Peterman, U. Pohlmann, and G. Huber, "Nearinfrared emission of $\mathrm{Cr}^{4+}$ doped garnates: lifetimes quantum efficiencies and emission cross sections," Phys. Rev. B 51, 17323-17331 (1995).

34. X.-G. Meng, J.-R. Qiu, M.-Y. Peng, D.-P. Chen, Q.-Z. Zhao, X.-W. Jiang, and C.-S. Zhu, "Near infrared broadband emission of bismuth-doped aluminophosphate glass," Opt. Express 13, 1628-1634 (2005).

35. Y. Ohishi, "Novel photonics materials for broadband lightwave processing," in Photonics West (SPIE, 2007). 